\title{
Modeling regional coral reef responses to global warming and changes in ocean chemistry: Caribbean case study
}

\author{
R. W. Buddemeier · Diana R. Lane · J. A. Martinich
}

Received: 11 May 2009 / Accepted: 3 December 2010 / Published online: 11 February 2011

(C) The Author(s) 2011. This article is published with open access at Springerlink.com

\begin{abstract}
Climatic change threatens the future of coral reefs in the Caribbean and the important ecosystem services they provide. We used a simulation model [Сомво ("COral Mortality and Bleaching Output")] to estimate future coral cover in the part of the eastern Caribbean impacted by a massive coral bleaching event in 2005 . Сомво calculates impacts of future climate change on coral reefs by combining impacts from long-term changes in average sea surface temperature (SST) and ocean acidification with impacts from episodic high temperature mortality (bleaching) events. We used mortality and heat dose data from the 2005 bleaching event to select historic temperature datasets, to use as a baseline for running Сомво under different future climate scenarios and sets of assumptions. Results suggest a bleak future for coral reefs in the eastern Caribbean. For three different emissions scenarios from the Intergovernmental Panel on Climate Change (IPCC; B1, A1B, and A1FI), coral cover on most Caribbean reefs is projected to drop below $5 \%$ by the year 2035 , if future mortality rates are equivalent to some of those observed in the 2005 event $(50 \%)$. For a scenario where corals gain an additional $1-1.5^{\circ} \mathrm{C}$ of heat tolerance through a shift in the algae that live in the coral tissue, coral cover above $5 \%$ is prolonged until 2065. Additional impacts such as storms or anthropogenic damage could result in declines in coral cover even faster than those projected here. These results suggest the need to identify and preserve the locations that are likely to have a higher resiliency to bleaching to save as many remnant populations of corals as possible in the face of projected wide-spread coral loss.
\end{abstract}

R. W. Buddemeier

Kansas Geological Survey, 1930 Constant Avenue, Lawrence, KS 66047, USA

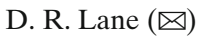

Stratus Consulting Inc., P.O. Box 4059, Boulder, CO 80306-4059, USA

e-mail: dlane@stratusconsulting.com

J. A. Martinich

Climate Change Division (6207-J), U.S. Environmental Protection Agency,

1200 Pennsylvania Avenue, NW, Washington, DC 20460, USA 


\section{Introduction}

The Caribbean is home to approximately 21,000-26,000 $\mathrm{km}^{2}$ of coral reefs (Burke and Maidens 2004; Spalding and Grenfell 1997). These coral reefs are ecologically diverse and complex ecosystems, providing a variety of ecosystem services [defined as the benefits that humans derive from these ecosystems (see Costanza et al. 1997)]. These ecosystem services, such as the provisioning of habitat for fish rearing, have ecological, cultural, and economic values (Millennium Ecosystem Assessment 2005). In the Caribbean, coral reefs provide an estimated $\$ 3.1-4.6$ billion annually (USD in 2000) in fishing, tourism, and shoreline protection services (Burke and Maidens 2004). Inclusion of ecosystem service values associated with biodiversity, bioprospecting, and other existence values could substantially increase these estimates (Burke and Maidens 2004; Llewellyn 1998).

The ecosystem services provided by coral reefs in the Caribbean are at risk from short-term and long-term threats to the structure and productivity of reefs (Burke and Maidens 2004). These risks are especially grave in the Caribbean, although similar risks exist for reefs worldwide (Knowlton 2001a). In late 2005, a massive coral bleaching event impacted reefs across the Eastern Caribbean. This event led to immediate mortality for some corals and additional mortality over the next few years, as corals made more vulnerable by bleaching succumbed to disease (Jeffrey et al. 2006; Rogers 2008; Rogers et al. 2008). Bleaching describes the process wherein reef-building corals lose their symbiotic, intracellular algae-these algae give corals their characteristic colors, but more importantly, also supply much of the host invertebrate's nutritional requirements through photosynthesis. Bleaching can occur when there are unusually high ocean temperatures combined with high light intensity and calm water conditions. Corals can recover from mild or moderate bleaching episodes by regaining their symbioses with intracellular algae, but prolonged, intense or repeated bleaching can prove fatal to the host coral.

Donner et al. (2007) analyzed and modeled the 2005 bleaching event and concluded not only that levels of thermal stress from SST were the highest ever recorded in the Caribbean in a satellite record extending from 1984-2005, but also that anthropogenic climate change played a clear role in causing this bleaching event. That is, the event would have been highly improbable in the absence of humaninfluenced ocean warming over the past several decades.

Given the importance of coral reefs to the economy and ecology of the Caribbean, there is a clear need to evaluate future risks to corals in this region from continued climate change impacts. In the long-term, climate change threatens reefs for two reasons: (1) increased acidification of the surface layer of the ocean, due to increasing atmospheric concentrations of carbon dioxide $\left(\mathrm{CO}_{2}\right)$, which makes it more difficult for corals to form their calcium carbonate skeletons (Kleypas et al. 1999; Langdon et al. 2000), and (2) rising ocean temperatures that increase the risk of coral bleaching, as already discussed (e.g., Donner et al. 2005; Hoegh-Guldberg 1999; Knowlton 2001a). The objectives of this manuscript are to provide a reasonable prediction of the effects of both actors on future coral cover, and especially of the risk of future bleaching-induced mortality in the part of the eastern Caribbean that experienced significant heat stress during the 2005 bleaching event (Fig. 1).

To conduct our analyses, we used the Сомво model, which integrates the impacts of future climate change (thermal and ocean chemistry effects) on coral growth and 


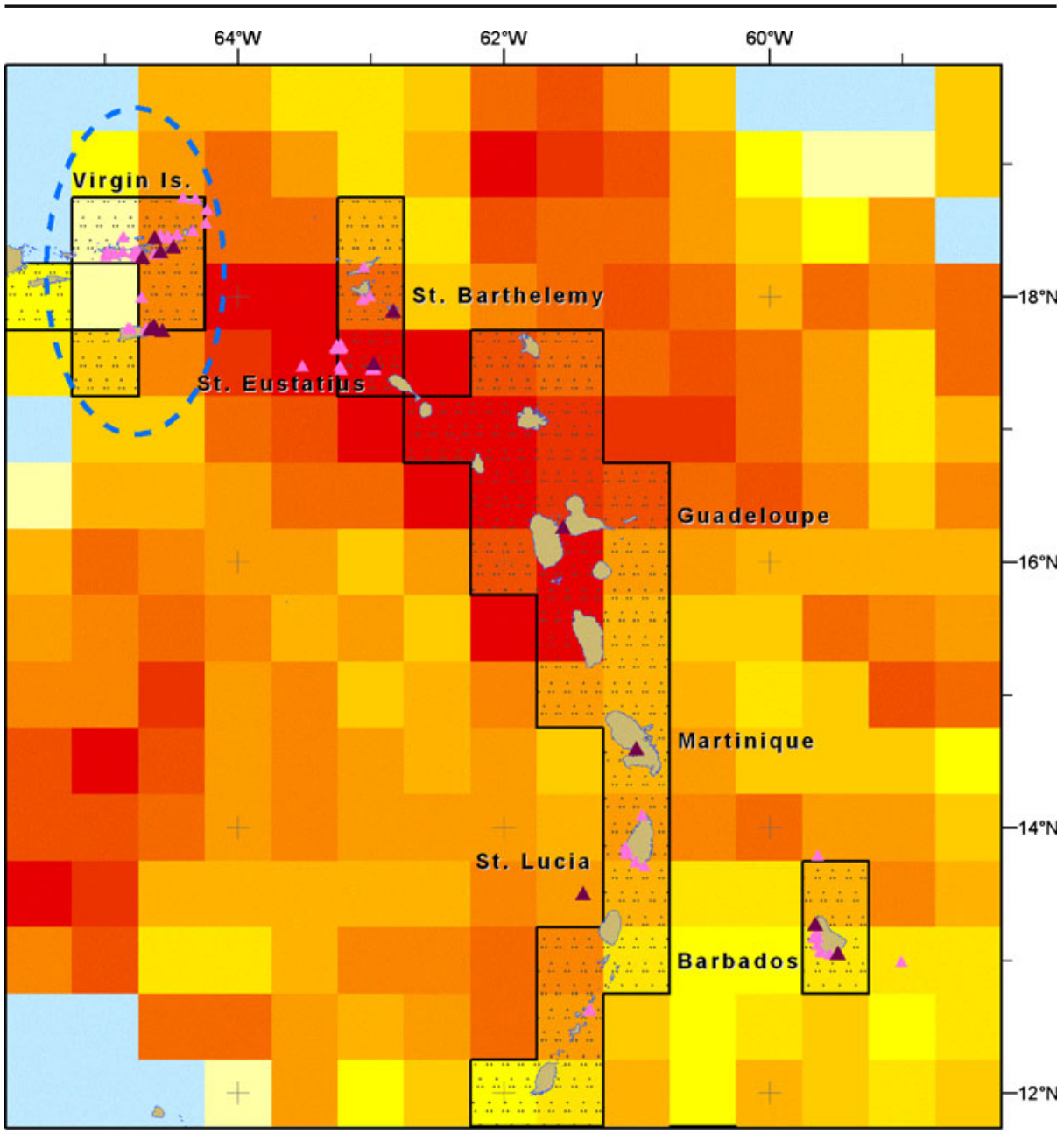

Max. Degree Heating Weeks (2005)

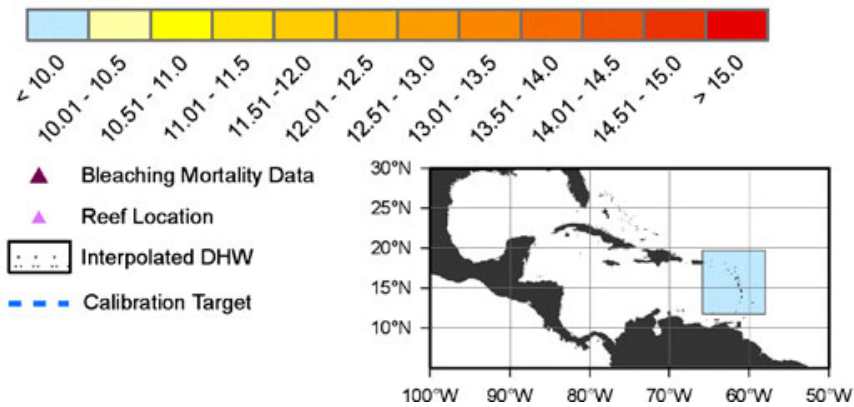

Fig. 1 Map of maximum 2005 heat dose (DHW) from the NOAA data archives, with the Virgin Islands area indicated. Dark triangles represent sites for which bleaching or mortality reports were available (see Table 1). Heat dose data were not available for the boxed and stippled cells because of the land-masses present in those cell; estimates for these cells and for all specific reef locations were generated by optimal interpolation (see text) 
mortality to estimate changes in coral cover over time (see Buddemeier et al. 2008). It incorporates impacts of high temperature events (bleaching-induced mortality) in the context of stresses to coral reefs caused by long-term changes in ocean temperature and chemistry. Сомво is designed to support "bottom-up" reef response modeling that considers the characteristics and histories of local reef communities. The model allows for different climate scenarios and coral reef sensitivities and explicitly provides a framework for incorporating potential coral acclimatization or adaptation to higher temperatures. This focus on actual coral mortality, as well as its user-friendly, flexible design, distinguishes Сомво from the "top-down" climate models that apply to large regional scales and are typically limited to predicting the recurrence of bleaching based on exceedences of a specified temperature condition (e.g., Donner et al. 2007; Hoegh-Guldberg 1999; Sheppard 2003). Сомво also is distinct from highly site-specific models that look at climate impacts on the survival of individual coral taxonomic groups (e.g., Riegl and Purkis 2009; Wooldridge and Done 2004) because it does not require specialized software or large taxonomic datasets and is designed for wide-spread use and application by field scientists or coral reef managers.

To calibrate selection of the historic temperature records that Сомво requires as inputs, we used heat-dose and coral mortality data from the 2005 bleaching event, primarily in the Virgin Islands and secondarily in the general eastern Caribbean. We then applied various scenarios and assumptions about future climate to examine the effect of future bleaching events on reefs with a range of coral cover values corresponding to values reported following the 2005 bleaching event. The results are used to discuss the likely future trajectory for coral reefs in the Virgin Islands and more generally in the eastern Caribbean. These results are of general interest as an illustration of future climate change impacts on a sensitive and important ecosystem that is already at risk from the ongoing climate change of the past few decades.

\section{Overview of model}

Сомво is a model that provides a probabilistic assessment of the effects of different future global climate scenarios on individual corals and on coral reef communities that have the extensive calcium carbonate structures typically associated with reefs. The model is configured to be most relevant to time scales of decades and spatial scales of hundreds of kilometers. The Сомво model is presented in detail in Buddemeier et al. (2008). The description that follows provides a brief overview of Сомво as context for the modeling results presented here.

The Сомво model provides estimates of changes in coral cover from 2000-2100 at monthly time-steps with results generally summarized and presented on an annual basis. Coral cover is considered a key index of the ability of coral communities to maintain or build coral reefs; a coral cover value of $50 \%$, for example, means that $50 \%$ of the ocean bottom at the specified ocean depth is covered with living coral. Changes in coral cover are indicative of the health of corals and coral communities and are calculated as the net difference between the rates of growth (including both growth of individuals and recruitment of new corals) and the rates of mortality from all causes.

The model consists of two interacting modules: a long-term change module and an episodic event module. The long-term change module calculates changes in the 
growth and mortality of corals over time in response to long-term changes in ocean chemistry and average SST. Superimposed on these long-term changes, the episodic event module calculates the impacts on coral cover of episodic mortality events such as those caused by severe coral bleaching.

\subsection{Long-term change module}

The long-term change module includes a growth function, a mortality function, and a function that accounts for the impacts of ocean acidification. The growth function is a cubic growth-temperature response curve, with the optimal temperature for growth adjusted to the long-term average (mean) monthly temperature value for the location being modeled. The mortality function is a linear equation that estimates direct high-temperature mortality not directly associated with episodic bleaching events (see Buddemeier et al. 2008 for details and derivation of both equations). In addition, the long-term change module calculates the effect on coral growth of changes in the ocean's carbonate saturation state with respect to aragonite, a calcium carbonate mineral that is the material from which coral skeletons are constructed. The aragonite saturation state is represented by the symbol $\Omega \mathrm{a}$ and is estimated from temperature and surface ocean water $\mathrm{CO}_{2}$ concentration in equilibrium with the known or assumed atmospheric concentration [see Buddemeier et al. (2008) for details of the calculation]. In general, as $\mathrm{CO}_{2}$ increases in the atmosphere and the ocean, $\Omega$ a decreases and coral growth is impeded. The sensitivity of corals to changes in $\Omega \mathrm{a}$ is defined in Сомво as a percentage decrease in growth per unit decrease in $\Omega \mathrm{a}$, relative to an assumed maximum growth rate at $\Omega \mathrm{a}=4.6$ (C. Langdon, U. Miami, personal communication). Sensitivities to changes in saturation state vary among taxa, and saturation state at the reef scale is variable and difficult to determine; the model therefore allows the user to select sensitivity levels to reflect local conditions (up to a maximum of a $40 \%$ decrease in growth per unit decrease in $\Omega$ a). Since this study takes a regional rather than a reef-specific view, we use scenarios to illustrate the possible range of effects.

\subsection{Episodic event module}

The episodic event module calculates coral mortality caused by up to three ${ }^{1}$ succes- $^{-}$ sive high-temperature bleaching events (identified as a, b, and c). The threshold dose for event $a$ is lower than for event $b$, which in turn is lower than for event $c$. This increase in threshold dose over time reflects the fact that the most heat-sensitive corals are successively lost from the community after each bleaching mortality event, resulting in a community-level "adaptation" to higher SSTs. The threshold doses for bleaching events $\mathrm{a}, \mathrm{b}$, and c correspond to specified heat-doses in units of degreeheating weeks (DHW). A dose of one DHW is defined as a SST that is $1^{\circ} \mathrm{C}$ above the local average bleaching threshold temperature for 1 week. A dose of three DHW could result from a summer SST that is $1^{\circ} \mathrm{C}$ above the threshold for 3 weeks or from a summer SST that is $3^{\circ} \mathrm{C}$ above the threshold for 1 week (or any other equivalent

\footnotetext{
${ }^{1}$ Сомво was designed with three events per model run to keep the model calculations simple; additional events can be added by running the model multiple times.
} 
combination of temperature and time). As a reference point, a dose of 10-12 DHW is a typical threshold for possible onset of bleaching mortality (Liu et al. 2003; Strong et al. 1997). When temperature data are available only at monthly time resolution, heat doses can be calculated in units of degree-heating months (DHM) and then converted to DHW, where one DHM is $\sim 4.3$ DHW and three DHM is $\sim 13.1 \mathrm{DHW}$.

The module calculates the cumulative probability that the summer heat dose experienced by corals will exceed the threshold doses set for bleaching events $a, b$, and c. When the cumulative probability of an event exceeds a specified level, then a "high-temperature" event is imposed. Calculation of the cumulative probability of bleaching is based on a procedure that involves sampling a long-term distribution of historic summertime temperature variations around the mean of the maximum annual summertime temperature (based on a 3-month average). The distribution is developed from historic SST records for the location being modeled. Details of the calculation method for cumulative probability are given in Buddemeier et al. (2008).

Сомво is designed with a high degree of user flexibility to allow for modeling different coral reef conditions and considering a variety of "what-if" scenarios. The following parameters in the episodic event module are defined by the user:

1. The cumulative probability level that triggers a bleaching event. For example, the user could select a highly likely event (the 90th percentile), an unlikely event (the 5th percentile), or an event with reasonable likelihood (the 50th percentile).

2. The fraction of high-temperature events that actually results in bleaching with coral mortality.

3. The mortality fraction associated with a bleaching event. A $50 \%$ mortality fraction (also referred to as a mortality rate) means that $50 \%$ of the current cover of corals would be lost after a bleaching event. For example, a reef with $20 \%$ cover would be reduced to $10 \%$ cover.

Parameter selections used for the modeling are discussed in Section 4.2.

\subsection{Integration of results}

Сомво calculates its results over time as changes in the percent of initial coral cover. During years when no episodic mortality event occurs, coral cover increases or decreases based on the difference between estimated growth and estimated mortality calculated in the long-term change module. When a bleaching-induced mortality event occurs, coral cover is reduced by the specified mortality fraction associated with that event. The model then continues the simulation with annual growth and mortality calculated by the long-term change module until another event occurs. Сомво provides a variety of outputs to the user, including plots and tables of changes in coral cover over time and of the cumulative probability of bleaching over time.

\section{Dataset selection-methods and results}

Сомво can be used with a variety of different long-term SST datasets; these datasets are needed in Сомво to estimate long-term monthly temperature patterns and to generate inter-annual distributions of summertime maximum temperature variations. We evaluated several long-term SST datasets with the goal of selecting datasets 
for use in future predictions based on how well they matched the heat-doses that were calculated in the Caribbean in 2005 by the near-real-time National Oceanic and Atmospheric Administration (NOAA) bleaching alert and warning system (NOAA 2008). The NOAA bleaching alert and warning system is regarded by the coral reef management community as the most easily accessible and widely-used source of bleaching and heat-dose data for corals world-wide. We wanted to select historical temperature datasets and parameters that would make our results from Сомво for the predictive modeling through 2100 as consistent as possible with the widely applied and understood NOAA-hotspot terminology and values for coral bleaching.

\subsection{Heat-dose and mortality data for 2005}

We compiled data on the original estimates of heat dose for the 2005 bleaching event from the NOAA data archives (http://coralreefwatch.noaa.gov/satellite/hdf/ index.html; Fig. 1; Table 1). The near-real-time bleaching alerts from NOAA do not provide dose estimates for any of the $0.5 \times 0.5^{\circ}$ grid cells that contain significant land, so heat doses for specific reef locations and for cell centers near land were interpolated from the nearest NOAA values using the Inverse Distance Weighting routine of the Geostatistical Analysis software extension of ArcInfo 9.3. We also obtained data on the prompt and long-term coral mortality following bleaching from Wilkinson and Souter (2008), Reefbase (www.reefbase.org), Bouchon et al. (2008), Oxenford et al. (2008), Woody et al. (2008), and other references cited in the text.

\subsection{Dataset selection methods}

We used a variety of different long-term SST datasets to calculate heat dose for 2005 for the average of the two Virgin Islands $1^{\circ}$ grid cells $\left(17-19^{\circ} \mathrm{N}, 164-165^{\circ} \mathrm{W}\right)$ where we had extensive mortality data (see Table 1 ). We compared the calculated results from these datasets with the NOAA calculated heat dose of 12.49 DHW for the average of the seven reef locations identified within the Virgin Islands (British Virgin Islands plus United States Virgin Islands). The long-term datasets we evaluated use a variety of sources and methods for conducting data reconstructions into the past, based on available SST observations. Details on the algorithms used in the different datasets for blending, smoothing, and adjusting the data are available from the references listed in Table 2.

Calculations of heat dose require: (1) an estimate of the bleaching threshold temperature for a reef (commonly some statistic related to the mean maximum monthly temperature), and (2) an estimate of the amount and duration by which the threshold is exceeded by the summertime maximum temperatures. For the data-set comparison, we compared the results from using different time periods for establishing the threshold temperature (e.g., 1982-1999 or 1900-1999) and from using two different methods for calculating heat dose: (1) by summing individual monthly doses for all consecutive months with positive DHW values; and (2) by calculating the 3-month dose. The 3-month dose is calculated using the hottest 3-month average SST as the estimate of maximum temperature, and the long-term average 3-month maximum SST as the threshold value. The default heat-dose calculation in Сомво uses the 3-month dose method, which produces a result similar but not identical to the 12 -week running mean dose calculated by NOAA. Because the datasets prior to 


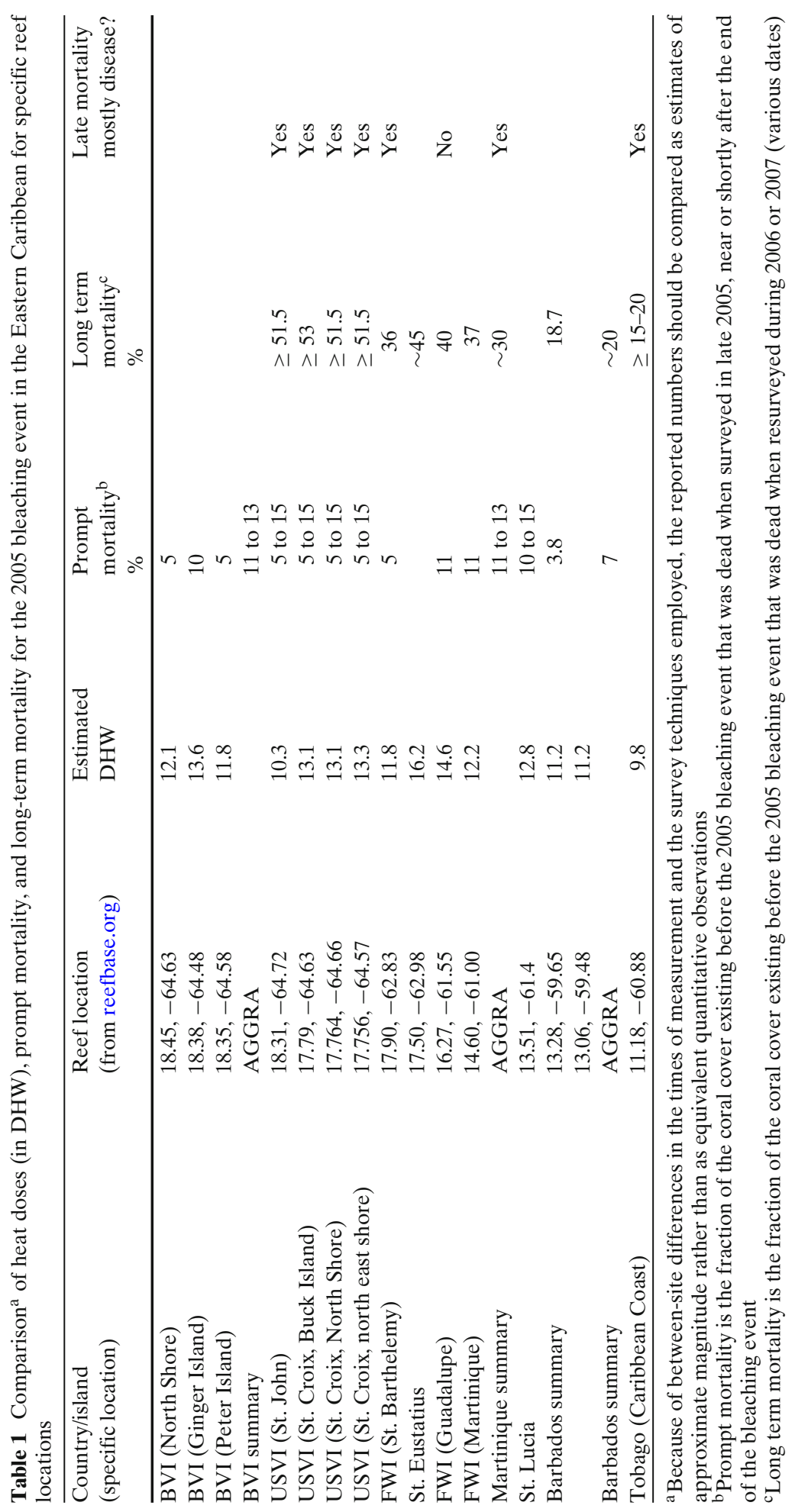


Table 2 Summary of long-term SST datasets and comparisons made for the dataset selection process

\begin{tabular}{|c|c|c|}
\hline $\begin{array}{l}\text { Dataset } \\
\text { abbreviation }\end{array}$ & $\begin{array}{l}\text { Time periods used to establish } \\
\text { threshold temperatures }\end{array}$ & Dataset notes and references \\
\hline $\mathrm{H} 1$ & 1900-1999; 1982-1999 & $\begin{array}{l}\text { SST data available in monthly } 1^{\circ} \text { area grids, } \\
\text { from } 1870 \text { to } 2008 \text { (Rayner et al. 2003; UK } \\
\text { Meteorological Office - Hadley Centre 2006). } \\
\text { Also known as "HadISST." }\end{array}$ \\
\hline $\mathrm{R} 2$ & 1900-1999; 1982-1999 & $\begin{array}{l}\text { SST data available in a monthly } 2^{\circ} \text { area grid, } \\
\text { from } 1854 \text { to } 2008 \text { (NOAA } 2009 \text {; Smith and } \\
\text { Reynolds 2004). Also known as "ERSST.v2." }\end{array}$ \\
\hline R1 & 1982-1999 & $\begin{array}{l}\text { SST data available in a monthly } 1^{\circ} \text { area grid, } \\
\text { from } 1981 \text { to } 2008 \text { (NOAA-IRI } 2009 \text {; Reynolds } \\
\text { et al. 2002). Also known as "Reynolds and Smith } \\
\text { Optimum Interpolation version 2" dataset, } \\
\text { or "OI.v2." }\end{array}$ \\
\hline V5 & $\begin{array}{l}\text { Only used for } 2005 \text { dose and } \\
\text { maximum temperature; } \\
\text { thresholds based on H1, R2, } \\
\text { and R1 data }\end{array}$ & $\begin{array}{l}\text { Satellite-based SST available in a monthly } 0.05^{\circ} \\
\text { area grid, from 1985-2005 (Casey and Cornillon } \\
\text { 1999; CoastWatch 2009; Kilpatrick et al. 2001; } \\
\text { Walton et al. 1998). }\end{array}$ \\
\hline
\end{tabular}

All threshold and dose values were calculated by both 3-month average and summed 1-month techniques

1982 are available only at monthly time resolution, all values were first calculated as DHM and then converted to DHW (one DHM is $\sim 4.3$ DHW; three DHM is $\sim 13.1$ DHW). Table 2 presents a summary of the comparisons made.

\subsection{Dataset selection results}

The closest match to the estimated average Virgin Island heat-dose of 12.49 DHW for the 2005 bleaching event (Table 1) was obtained by using the R2 dataset, the 19821999 time period for establishing threshold temperatures, and the 3-month average approach for calculating dose (Table 3). This combination of parameters resulted in a heat-dose estimate of 12.36 DHW, which matches the NOAA estimate of 12.49 DHW obtained from the near-real time AVHRR data very well. We emphasize that the objective of the dataset selection exercise is not to produce the most accurate or precise after-the-fact determination of heat stresses, but to test and demonstrate techniques that can be readily and promptly applied by non-specialist scientists and managers. The Pathfinder V5 data, for example, is probably the most accurate source of SST information. However, this is available a year after the fact, while the R1 and R2 datasets (for example) are updated monthly, and R2 provides long-term retrospective temperature estimates.

For the exercise here, we found that the heat dose estimates involving the Hadley H1 data ranged from 6-9 DHW, which were substantially lower than the original NOAA estimates. Heat dose estimates using the different combinations of Reynolds data (R1 and R2) ranged from 12-16 DHW, while the Pathfinder (V5) data in combination with the different threshold datasets provided heat dose estimates from 11-16 DHW. In general, the maximum 3-month average approach matched the NOAA estimates better than the summed individual month doses (Table 3). Although we found that the R2 dataset provided the best match to the NOAA estimates for the 
Table 3 Comparison of estimated heat-doses for the 2005 Virgin Islands bleaching event using various SST datasets with 3- and 1-month summed dose calculations

\begin{tabular}{|c|c|c|c|c|c|c|c|c|}
\hline \multirow{3}{*}{$\begin{array}{l}\text { Dataset }^{\mathrm{a}} \text { and time } \\
\text { period used for } \\
\text { threshold } \\
\text { temperature }\end{array}$} & \multicolumn{8}{|c|}{$\begin{array}{l}\text { Heat-dose in DHW for combinations of different threshold temperatures } \\
\text { with } 3 \text {-month maximum }(-3 \mathrm{~m}) \text { and summed } 1 \text {-month maximum }(-1 \mathrm{~m}) \\
2005 \text { temperatures from the indicated datasets }\end{array}$} \\
\hline & \multicolumn{4}{|c|}{ 1-month summed dose method } & \multicolumn{4}{|c|}{ 3-month averaged dose method } \\
\hline & V5 & H1 & R1 & $\mathrm{R} 2$ & V5 & $\mathrm{H} 1$ & $\mathrm{R} 1$ & $\mathrm{R} 2$ \\
\hline \multicolumn{9}{|l|}{ 1900-1999 } \\
\hline H1 & 11.59 & 7.85 & nd & nd & 13.71 & 8.52 & nd & nd \\
\hline $\mathrm{R} 2$ & 15.52 & nd & nd & 16.99 & 16.22 & nd & nd & 14.45 \\
\hline \multicolumn{9}{|l|}{ 1982-1999 } \\
\hline $\mathrm{H} 1$ & 11.00 & 7.16 & nd & nd & 13.34 & 8.38 & nd & nd \\
\hline $\mathrm{R} 1$ & 11.52 & nd & 13.03 & nd & 13.8 & nd & 13.97 & nd \\
\hline $\mathrm{R} 2$ & 11.97 & nd & nd & 13.33 & 14.12 & nd & nd & 12.36 \\
\hline
\end{tabular}

See text for details

$n d$ no data (comparison not calculated)

${ }^{\text {a }}$ Dataset abbreviations defined in Table 2

Virgin Islands, we are not concluding that this dataset is the optimal selection for all locations. Rather, it is the method of dataset selection demonstrated here-testing a variety of datasets, threshold time periods, and calculation methods-that will allow a user to identify the most appropriate temperature dataset and parameters for their specific location and need.

\subsection{Selection of results thresholds}

The Сомво model focuses on changes in live coral cover as the key metric for defining the health of coral communities. Specifically, we use 5-10\% live coral cover as an informal threshold range within (or below) which a community can no longer be considered a "coral reef" community that accretes carbonate and has the identifiable structure of a reef, but instead should be considered a shallow-water ecosystem that contains individual coral organisms. In order to form a coral reef, a coral reef community must accrete carbonate substrate. As calcification rates and coral cover decline in response to climatic and other stresses, the question of when a coral community is no longer a reef-building community is increasingly a concern (Kleypas et al. 2001).

Because many factors other than coral cover and growth affect the carbonate budget, a strict relationship cannot be determined, but reasonable limits have been estimated. Buddemeier and Smith (1988) reviewed the literature on geologic reef accretion and on coral and community calcification. They identified a "consensus maximum" rate of $10 \mathrm{~mm} / \mathrm{year}$ that was consistent with all of the datasets examined. Biogeochemical studies of community calcification (the alkalinity method, reviewed and summarized by Kinsey 1985) identified modal values, with the highest mode equivalent to an accretion rate of $7 \mathrm{~mm} /$ year on average; the highest measured value was $9 \mathrm{~mm} / \mathrm{year}$. This high mode applied to coral thickets, $\sim 100 \%$ cover, and expressed as an extension rate, is of the same magnitude as the growth rates of massive corals. The regional background modal rate is equivalent to $0.6 \mathrm{~mm} / \mathrm{year}$, or slightly less than $10 \%$ of the high mode value. We therefore estimate that a coral cover of $5-10 \%$ can be considered unlikely to accumulate significant endogenous 
carbonate, although depending on growth rate and environmental factors, even cover values considerably higher may not be associated with any net reef development (e.g., Harriott and Banks 2002).

\section{Future climate effects: methods and results}

This section describes the methods used and the results obtained from modeling coral reef responses to different scenarios of expected increases in ocean temperature and $\mathrm{CO}_{2}$ concentration over the next century.

\subsection{Future climate scenarios}

Future $\mathrm{CO}_{2}$ and temperature scenarios were obtained from the MAGICC/ SCENGEN (v. 4.1) global climate model (Wigley 2004). MAGICC is the "Model for the Assessment of Greenhouse-gas Induced Climate Change" and is a coupled gas-cycle/climate model used by the IPCC to project future increases in global mean temperature and sea level rise for the Third Assessment Report, or TAR (IPCC 2001). SCENGEN, which is a "Global and Regional Climate SCENario GENerator," combines results from MAGICC with regional climate change patterns to create spatially explicit patterns of temperature change for a common $5^{\circ}$ latitude/longitude grid (Wigley 2004). Temperatures are lower atmosphere temperatures because SSTs are not available from the MAGICC/SCENGEN model. However, tests of these predictions against modeled future SST values have shown differences $<0.2^{\circ} \mathrm{C}$ for the locations of interest (Buddemeier et al. 2008).

For the modeling results presented here, results for the $5^{\circ}$ cell centered at $17.5^{\circ}$ $\mathrm{N}, 62.5^{\circ} \mathrm{W}$ were obtained from MAGICC/SCENGEN for three emissions scenarios used in the IPCC AR4 (IPCC 2007). The emissions scenarios and their predicted atmospheric $\mathrm{CO}_{2}$ concentrations in 2100 are: B1 (540 ppm), A1B (703 ppm), and A1FI (958 ppm). Each scenario was run assuming a $3^{\circ} \mathrm{C}$ climate sensitivity to doubling of the preindustrial $\mathrm{CO}_{2}$ concentration of $280 \mathrm{ppm}$, which was the "most likely sensitivity" reported in AR4 (IPCC 2007). For each scenario, $\mathrm{CO}_{2}$ concentrations were obtained at 5-year intervals, and predicted temperatures were provided as ${ }^{\circ} \mathrm{C}$ above the temperature in the year 2000. We obtained predicted temperatures for the years 2000, 2020, 2030, 2050, 2075, and 2100. Linear interpolation was used between these values to estimate predicted annual values of temperature and $\mathrm{CO}_{2}$; the effects of both were calculated concurrently and combined (see Section 4.3).

\subsection{Modeling procedures}

Historic climate data are used to estimate several parameters used as input to Сомво. The R2 dataset for the years 1982-1999 was found (see Section 3.3) to provide the estimate of bleaching threshold (average 3-month maximum SST) that best reproduced the Virgin Islands heat dose data. For consistency, the R2 dataset was also used for the other inputs: (1) Average monthly temperatures, calculated from the 1990-1999 data subset in recognition of changing monthly temperature patterns in recent decades with higher summer-time maximum temperatures; (2) The longterm distribution of temperature variations around the mean of the maximum annual 
average 3-month temperature, which is used to calculate the probability that the bleaching threshold temperature will be exceeded in a given year (see Section 2.2); and (3) long term temperature maximum, minimum and variability statistics used as input to the equations relating coral growth and non-bleaching mortality to temperature. For the latter two applications, the 1900-1999 data subset was used to provide a stronger statistical basis for these parameter values, which represent the results of long-term biological adaptation and/or acclimatization.

We assumed for the baseline year of 2000 that baseline growth and mortality rates were equal and were set at $0.33 \% /$ month, for total steady-state initial growth and mortality rates of $4 \%$ for the year. Because we did not have specific information on the saturation state sensitivity of corals in the eastern Caribbean, in the modeling runs we compared rates of $\Omega$ a saturation state sensitivity of $0,20 \%$, and $40 \%$ (very low, moderate, and high sensitivities).

For the episodic event module, the threshold temperatures for three successive modeled bleaching events ("a, b, and c") were set as follows. The initial threshold temperature (event a) was set at $29.5^{\circ} \mathrm{C}$ - this represents a heat dose of $12.31 \mathrm{DHW}$ for 3 months, given the baseline mean maximum 3-month temperature value of $28.56^{\circ} \mathrm{C}$, calculated using the $\mathrm{R} 2$ temperature dataset for $1982-1999$. This heat dose is in the central range estimated for the 2005 bleaching event in the Eastern Caribbean in general, and the Virgin Islands in particular. The first modeled bleaching event would thus be approximately the same as the 2005 event in terms of dose. For subsequent bleaching events, the threshold temperatures for events $\mathrm{b}$ and $\mathrm{c}$ were set progressively $0.2^{\circ}$ higher than the preceding threshold ( $\sim 2.6$ additional DHW), based on the assumption that this is the approximate dose increment required to inflict comparable damage on a community from which the most vulnerable corals have already been removed and where only the more tolerant corals remain.

For this modeling exercise, the probability of a bleaching event calculated by Сомво on the basis of the predicted temperature and the historic distribution of variation was multiplied by a bleaching factor of $50 \%$, representing the fraction of the specified high-temperature that were assumed to result in the indicated mortality. When the modified occurrence probability reached 50\%, cover was reduced by the selected Mortality Factor, which was modeled as either $15 \%$ (the typical short-term average mortality estimate from the 2005 event), or $50 \%$, which approximates the upper-end of the reported mortality estimates from the 2005 event after disease compounded the effects of bleaching (see Table 1).

We conducted a specific set of model simulations to address the question of adaptive responses by individual organisms or taxa. Under thermal stress, some corals may undergo a shift in the dominant symbiotic alga (e.g., from C to D clade) (Baker et al. 2008; Jones et al. 2008; Thornhill et al. 2006), which can confer an additional $1-1.5^{\circ}$ of heat tolerance on the coral-algal combination (the "holobiont"). However, the new symbiosis is subject to reversion (with an apparent time constant of a few years) to dominance by the more sensitive alga if the high temperature stress is removed. These special simulations represented the effects of the following assumptions:

- The heat-resistant algal symbiosis becomes stabilized when an 8 DHW dose has a $50 \%$ probability (i.e., substantial bleaching but only minor mortality about every other year). 
- For the part of the population affected, the bleaching threshold becomes one degree higher after the new algal symbiosis is stabilized.

\subsection{Modeling results}

We first illustrate the effects of various parameters on the outcomes of modeling coral cover changes, and then present what we consider the most likely outcome in terms of actual reef responses to future climate. For several of these modeling scenarios, we use starting levels of coral cover of $7 \%, 15 \%$, and/or $30 \%$ cover. These values represent a broad range that should allow the reader to approximate centerpoints of the low-end, average, and high-end ranges of coral cover in the Virgin Islands after the 2005 bleaching event (Rogers et al. 2008). Figure 2 illustrates the effects of mortality and growth scenario selection on modeled cover change due to future climate change. This analysis assumed an initial coral cover of $30 \%$ and used the A1B emission scenario, defined by the IPCC as a medium emissions growth storyline of very rapid economic growth, global population growth peaking at midcentury, and a balanced reliance on various energy sources (IPCC 2007). The first three modeling runs disabled the episodic events module and Fig. 2a shows the effects on coral cover of a gradual temperature increase and three different sensitivities to saturation state. Line A is SST only ( $\Omega$ a sensitivity $=0$ ), while lines B and C represent sensitivities of $20 \%$ and $40 \%$ respectively (fractional decrease in growth for doubled $\mathrm{CO}_{2}$ ). The fourth scenario (line "D") projects the effect on coral cover of $15 \%$ mortality per event, with $20 \%$ sensitivity to changes in saturation state. Note that for these scenarios, Сомво was run two times in succession to allow six bleaching events to occur. The fifth scenario (represented by "E") illustrates a mortality factor of $50 \%$ per event.

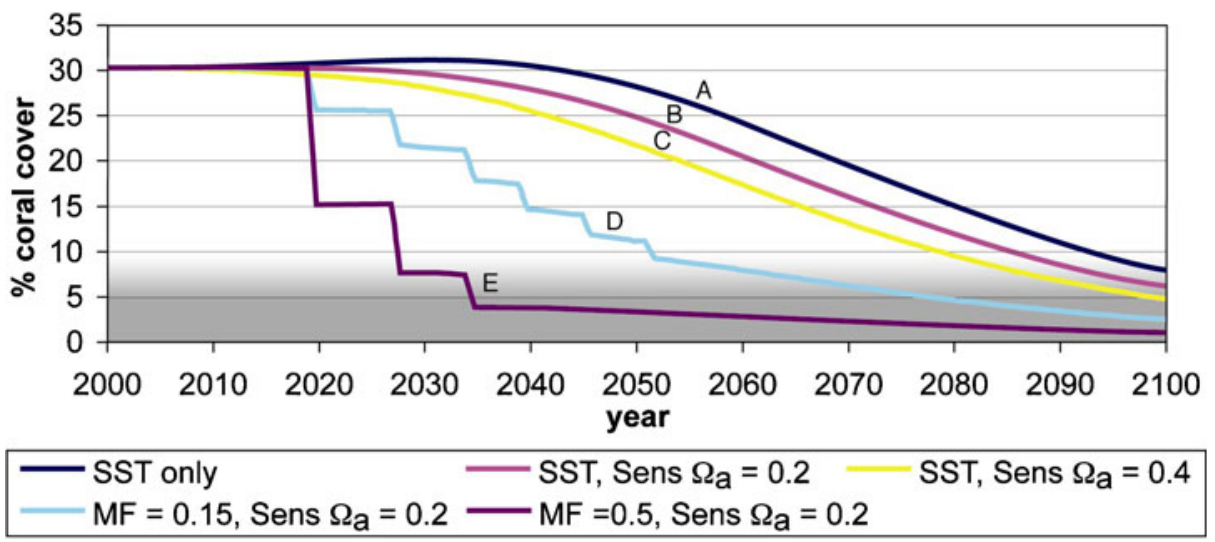

Fig. 2 The effects of various mortality and growth scenarios on a coral community with an initial $30 \%$ cover. The initial dose is $12.3 \mathrm{DHW}$, and subsequent thresholds are progressively $2.6 \mathrm{DHW}$ higher; other than this threshold increase, no adaptation is assumed. The A1B climate scenario and the temperature datasets identified in the text are used. $A$ Projected effects on growth of gradual SST increase (no bleaching events) and no $\Omega$ effect. $B$ SST effects, with moderate $\Omega$ sensitivity $(0.2)$. $C$ SST effects, with high $\Omega$ sensitivity (0.4). D $15 \%$ mortality per event with moderate $\Omega$ sensitivity (0.2). $E$ as in $D$, but with $50 \%$ mortality per event 
Even without high-temperature bleaching and mortality events, this scenario depicts a decline in coral cover below 10\% (our proposed informal threshold for reefs considered unlikely to accumulate significant endogenous carbonate) by the year 2085. As can be seen in Fig. 2, the direct effects on corals of changes in saturation state sensitivity (from a minimum of zero to a maximum of $40 \%$ ) are minor compared to the effects of high temperature-both mortality events and growth decline. For a modeling scenario where a reef began with $30 \%$ initial cover and a mortality factor of $15 \%$, coral cover falls below $10 \%$ by 2055 . When the mortality factor is set to $50 \%$, coral cover falls below $10 \%$ by 2035 . An initial cover of $30 \%$ is a relatively high value for the post-2005 Virgin Islands, suggesting that some reefs will experience a fall in coral cover below $10 \%$ at even earlier dates. The goal of using these parameters is not to make firm quantitative predictions but instead to allow the reader to make semi-quantitative relative comparisons to their reefs of interest, based on local initial cover and sensitivity.

Figure 3 compares the effects on coral cover of the temperature and $\mathrm{CO}_{2}$ changes associated with the different emissions scenarios shown in Fig. 3a, both with and without adaptive responses by individual coral organisms or taxa (Fig. 3b) and using different event probabilities (Fig. 3c). The model runs with no adaptation (solid lines, Fig. 3b), make it clear that there is little difference in outcomes between the three different IPCC emissions scenarios (B1, A1B, and A1FI). For all three climate scenarios, if $50 \%$ mortality events are assumed, cover drops below $5 \%$ by the year 2035 . If corals are able to gain an additional $1^{\circ}$ of heat tolerance (dashed lines, Fig. 3b-see Section 4.2 for details of model simulations), then survival of corals above the $5 \%$ level is prolonged until approximately 2065 . There is a notable difference across the three emissions scenarios starting approximately in 2050 (Fig. 3a), with the lowest emissions and highest coral cover associated with the B1 scenario, and the highest emissions and lowest coral cover associated with the A1FI scenario (compare $3 b$ with 3a).

In Fig. 3c, a hypothetical "no climate change after the year 2000" is added for comparison, where the temperature and saturation state are constant at the 2000 values. The occurrence of a bleaching event in this "no further change" scenario indicates that the heat dose in 2000 had already entered the probability distribution for bleaching, and eventually the accumulating probability brought it to the $P=0.5$ level. In other words, even if climate change had stopped in 2000 and there were no further human-induced increases in temperature or $\mathrm{CO}_{2}$, there would still be a $50 \%$ probability of a major mortality event in the Eastern Caribbean by approximately the year 2055 .

Another comparison in Fig. 3c illustrates the effect of statistical variation or "outlier" events on the timing of bleaching occurrences. Plots show the A1B scenario trajectory for $10 \%, 50 \%$ and $90 \%$ cumulative bleaching event probability; for comparison, Сомво calculates the 2005 probability of the actual event as having been $\sim 7.9 \%$. The two extreme probability values span a range of about 20 years for the time of a given event.

The results depicted in Fig. $3 \mathrm{~b}$ and c show very small differences in coral outcome between the three climate scenarios that represent different levels of greenhouse gas (GHG) emissions. These results suggest that it matters little to the fate of corals in the Eastern Caribbean in the next 30-50 years whether humans are able to reduce emissions to the level predicted in the "optimistic" B1 scenario. The role of chance 

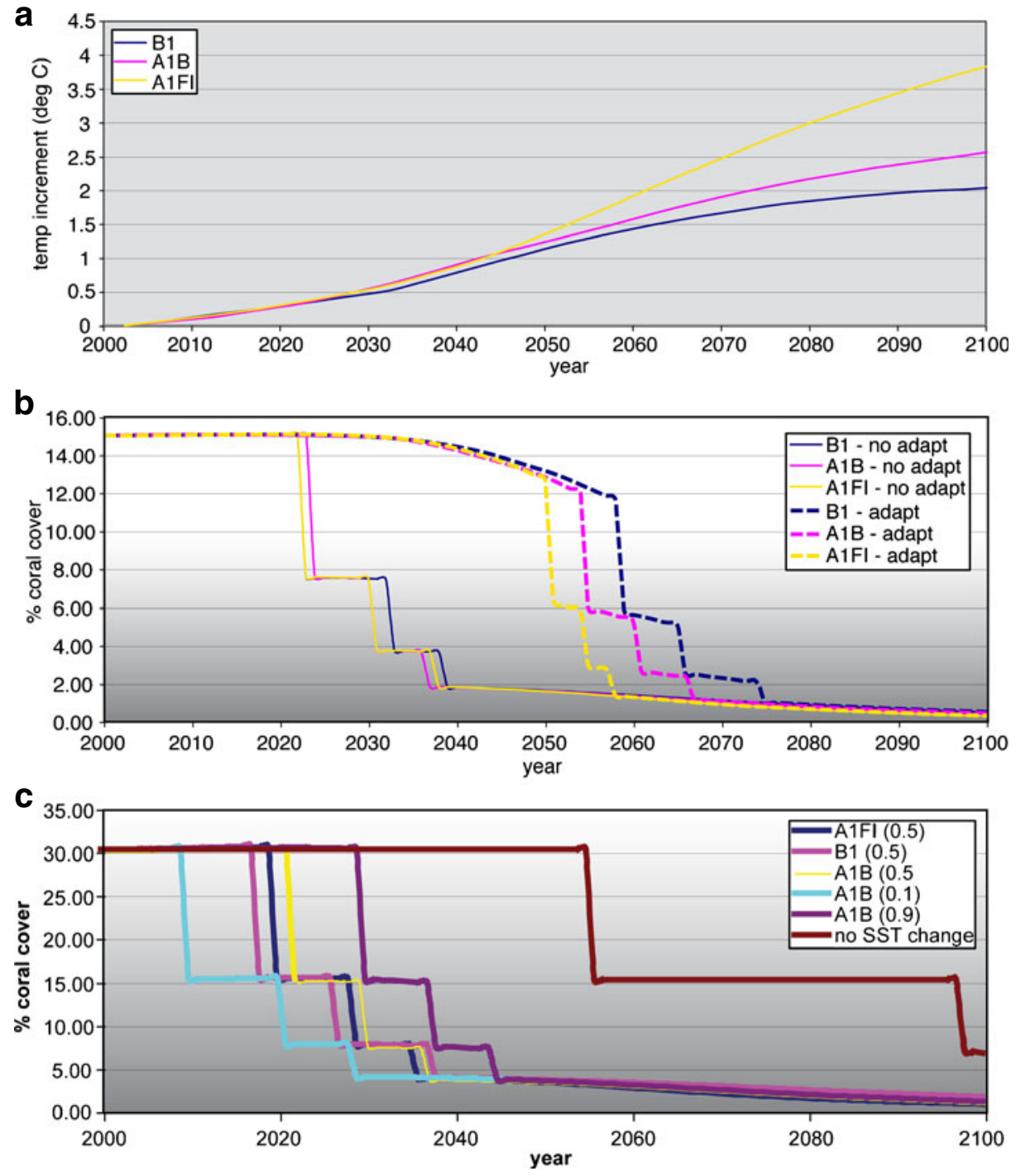

Fig. 3 Results of model analysis of factors controlling future coral cover in the Eastern Caribbean. All mortality factors are $50 \%$ per event. a Three different IPCC temperature scenarios (B1, A1B, A1FI, representing low, business-as-usual, and high scenarios, respectively). b Illustration of the effects of coral adaptation to higher temperatures for trajectories defined by the three climate scenarios over the century. c Comparison of the three scenarios with a "no-further change" assumption, and the 0.1 and 0.9 occurrence probabilities for the A1B scenario as well as the usual $P=0.5$

(Fig. 3c), rather than human actions, is likely to dictate the timing of coral decline in the Eastern Caribbean over the next 30-50 years.

Figure 4 depicts the modeled trajectory of coral cover over the next century in the Eastern Caribbean for three different starting levels of coral cover, $7 \%, 15 \%$, 


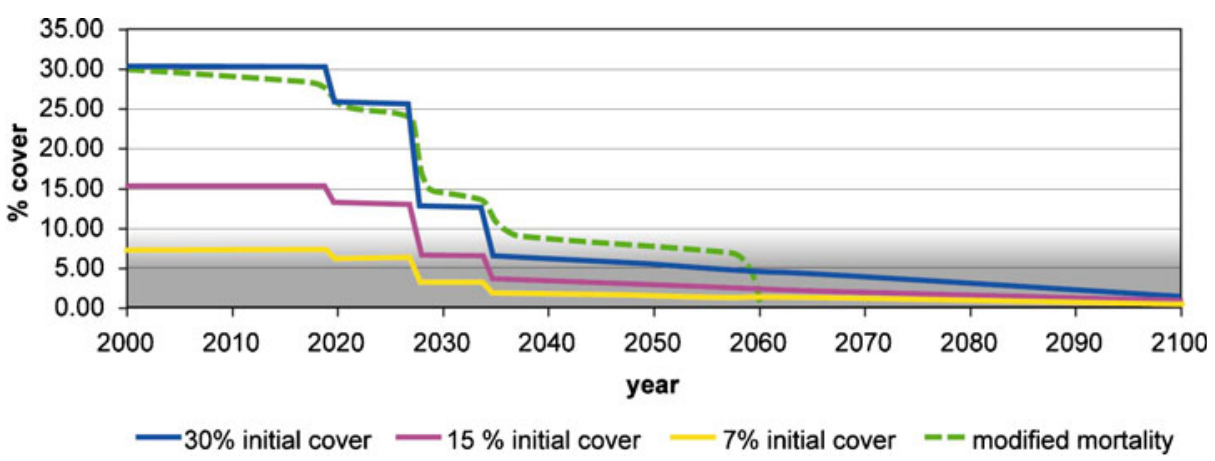

Fig. 4 Results of future climate modeling for the Eastern Caribbean showing the modeled trajectory of coral cover for three initial cover classes-30\%, $15 \%$, and $7 \%$, with mortality factors of $0.15,0.50$, and 0.50 . The green dashed line suggests how other factors might modify the pattern shown by the $30 \%$ initial cover line See text for additional details

and $30 \%$, using the A1B climate scenario. These values represent a broad range that should allow the reader to approximate center-points of the low-end, average, and high-end ranges of coral cover in the Virgin Islands after the 2005 bleaching event (Rogers et al. 2008). The first event occurs with a heat-dose that is a repeat of the 2005 event, and is therefore assigned a lower mortality factor (15\%) because the most susceptible corals already died in the 2005 event. The succeeding events occur with increasing heat-doses of approximately 2.6 DHW at each step and are each assigned a long-term mortality factor of $50 \%$, which was comparable to the 2005 event (see Table 1 and Section 4.2 for more discussion of the mortality factors). All assume a mid-range $\Omega$ saturation state sensitivity of 0.2 . For all three starting cover classes, Fig. 4 depicts coral cover to fall below $10 \%$ by 2035 or earlier, and below $5 \%$ by 2050. However, these lines consider only thermal (and associated disease) mortality, and do not consider adaptation. The additional dashed line (initial coral cover of $30 \%$ ) represents a conceptual illustration of the possible effects of other sources of mortality—storms, anthropogenic damage, and endemic disease cause more rapid declines, while the potential for adaptation in a fraction of the population raises the "tail" of population curve.

\section{Discussion}

The modeling results presented here suggest that future prospects for coral reef communities in the Southeast Caribbean are bleak. Coral reef communities are likely to be essentially gone from substantial parts of the Southeast Caribbean by the year 2035, given the current low cover values following the 2005 event. In the remainder of the Section 5, we first examine the uncertainties associated with these results and the possible biases of the data and assumptions used. Then we consider the implications of the modeling results.

A key question is whether the results presented here are specific to the Virgin Islands area or if they can be extrapolated to the chain of coral reefs of the Lesser Antilles, within the Southeast Caribbean. We suggest there is strong evidence that 
the modeling results can be reasonably extrapolated to the Southeast Caribbean, with caveats noted below. For the 2005 bleaching event, there was remarkable similarity in the independent reports of the timing, depth profiles, and magnitude of coral bleaching and mortality over the entire island arc of the Lesser Antilles. Although there were local variations, we feel that the broad regional similarities in heat doses and mortality responses justify extrapolations from the Virgin Islands to the Southeast Caribbean region. The Virgin Islands area was used to calibrate doseresponse relationships, both because it is a particularly well-documented area and because the heat doses were generally similar to most of the islands. To model other locations in the Southeast Caribbean, initial coral cover values appropriate to those areas would need to be used, but the cover trajectories can be reasonably estimated as proportional to the values plotted here (Fig. 1, Table 1).

The caveat to this extrapolation is that the Сомво model was used here as it was designed to be used-applied to a discrete region with dimensions of no more than a few hundred kilometers. Although we believe that the high-level predictions made by the model will apply across the Southeast Caribbean, modeling results for other specific reef locations shown in Fig. 1 would not be identical to the Virgin Islands because of differences in the site-specific thermal histories that provide the temperature patterns and distributions used in the model.

\subsection{Uncertainties}

With respect to the specific predictions made by the model as presented in Fig. 4, there are uncertainties that could cause the model to be unduly pessimistic or unduly optimistic with respect to the timing of bleaching events and the magnitude of mortality. These factors are summarized below.

Factors that would contribute to greater rates of coral survival compared to model predictions:

- Adaptation. The model-generated predictions of Fig. 4 (solid lines) did not factor in possible adaptation of corals to higher temperatures. If adaptation does occur, it would likely be limited to a modest subset of the corals, but adaptation could raise the cover estimates by a few percent and extend the survival curves for a few additional decades (see Fig. 4 dashed line for a conceptual illustration of the effect).

- Survival of deep reefs. We did not model climate change impacts on deep reefs (>30 $\mathrm{m}$ below the ocean surface), some of which survived the 2005 bleaching event with substantial cover (Rogers et al. 2008).

- Lower mortality rates. The Virgin Islands long-term mortality figures after the 2005 bleaching event ( $>50 \%$ ) were at the high end of the regional estimatesother sites were mostly between $30 \%$ and $50 \%$ (Table 1), and those with lower doses (Barbados, Tobago), were even lower. Therefore, our use of $50 \%$ mortality for future bleaching events may be unduly pessimistic.

Factors that would contribute to lower rates of coral survival compared to model predictions:

- Additional sources of mortality. Only bleaching mortality and bleachingenhanced disease mortality were considered. The histories presented in Wilkinson and Souter (2008) and by Rogers et al. (2008) indicate substantial 
recent past losses of coral cover due to hurricanes, human activities, and "background" diseases. Baker et al. (2008) point out the recent history of corals in the Caribbean has been one of consistent decline unrelieved by episodes of recovery such as have been observed elsewhere. We see no reason to think these trends will not continue (see regional assessment by Smith and Buddemeier 1992, p. 110).

- Additional impacts from ocean acidification. With regard to ocean acidification, only growth inhibition of the corals was considered. Large-scale ecosystem effects of acidification were not considered and could easily contribute to community deterioration with feedback to the corals. These potential ecosystem impacts include the potential rapid loss of an important group of ocean organisms (e.g., the coralline algae, which construct skeletons with highly soluble high-magnesium calcite), or interference from acidification on functions such as reproduction or maturation in a wide range of ocean organisms (see Vezina and Hoegh-Guldberg 2008).

- Increased temperature variability over the next century. Сомво uses the distribution of high temperatures over the past century to model high temperature variations into the future. Under conditions of climate change, an increase in variability is plausible; this would increase the likelihood of bleaching events and cause the events, on average, to happen earlier.

- Additional high temperature event stress. Сомво is structured so that each successive mortality event represents an increase in dose intensity. Therefore, the potential impacts on corals from high temperature events that are below the next threshold value are not considered-these are likely to be a source of significant stress, and probably some mortality, especially if they are closely spaced in time.

- Pattern and starting temperature biases. 1991 and 1992 may have been cooler than would otherwise be expected because of volcanic eruptions; these years have been omitted from the threshold baseline used by NOAA (http://www.osdpd. noaa.gov/PSB/EPS/SST/methodology.html\#dhw). Either a higher average or a higher maximum value in the monthly pattern used would accelerate the impacts.

- Changes in baseline growth and mortality. The "baseline" growth and mortality values in Сомво are held constant across the modeling time period, which is definitely optimistic in a deteriorating environment. Note also that there is significant uncertainty in their assigned initial values.

- Direct effects of climate change on reproduction and recruitment. Сомво models the impacts of climate change on coral mortality, but does not consider the potential impacts of climate change on coral reproduction and recruitment. Declines in reproduction and recruitment would make recovery after bleaching events slower than the model predicts.

Factors that add uncertainty to model predictions, but the direction of the potential bias is not clear:

- Long-term growth and mortality functions. The long-term growth and mortality functions in Сомво (see Section 2.1) were developed from experimental results on coral taxa native to Hawai'i, and modified with local Caribbean parameter values. The direct effects of increased temperature on the growth and mortality of coral taxa in the Caribbean (independent of bleaching) are not 
explicitly known. Uncertainty in these parameters, however, has little leverage on model outcomes because the bleaching events are the overwhelming source of mortality.

- Threshold temperatures for additional bleaching events. Selection of threshold temperatures for successive bleaching events is based on our best estimates of coral tolerance. The 2005 data show that there were some hardy corals that did not bleach in 2005- the dose at which these corals will be susceptible to bleaching is unknown. Our estimates may either over-predict or under-predict the heat tolerance of these corals.

- Selection of temperature datasets for model use. The dataset selection exercise is described in detail in Section 3. Selection of a temperature dataset different from the R2 dataset actually adopted would have changed the timing of predicted bleaching events by 20 to 30 years (either earlier or later, depending on the dataset selected).

In general, given the uncertainties listed above, it is more likely the model predictions are unduly optimistic with respect to the overall rates and patterns of coral and reef loss.

\subsection{Implications}

The United Nations Framework Convention on Climate Change calls on parties to limit GHG concentrations to a level that avoids dangerous climate change, including the crossing of critical ecosystem thresholds (UNFCCC 2009). When the cover of coral on a reef is just $5 \%$ to $10 \%$, there are many reasons to believe that a critical threshold has indeed been crossed. On an a priori basis, it seems clear that communities with $<10 \%$ cover are extremely unlikely to be accreting carbonate, and whether one would call them reef communities at all would depend on the overall composition. Decreasing coral cover is often accompanied by increases in the cover of macroalgae, suggesting that a qualitative shift in the coral community occurs with decreasing coral cover (Rogers et al. 2008). Monitored sites in the Caribbean that currently have $<10 \%$ live scleractinian coral cover (e.g., Causey 2008; Rogers et al. 2008), appear to still be categorized as "reef" or "reef communities" for historical reasons - in the 1970s and before they had several times that proportion of coral cover. Using an analogy to terrestrial ecosystems, it is clear that we would not call land cover with less than $5 \%$ or $10 \%$ tree cover a "forest," even if the land had been forested at some point in the past.

Our modeling results suggest that coral ecosystems in the Caribbean will cross critical thresholds within the next several decades, if not before. For example, the modeling results in Fig. 4 show coral cover for the Eastern Caribbean declining below $5 \%$ by approximately 2035 , using moderate assumptions for climate change (e.g., A1B scenario, mid-range sensitivity to saturation state) and the mortality responses already observed after the 2005 event. Furthermore, the results presented in Section 4.3 suggest that future actions to reduce GHG emissions may have little influence on coral bleaching mortality in the Caribbean, which has already been identified as an area especially vulnerable relative to the Indo-Pacific because of its setting and evolutionary history (Smith and Buddemeier 1992) and its failure to demonstrate recovery from previous coral cover losses (Baker et al. 2008). Climate change impacts to date, along with impacts yet to be realized due to past and current 
emissions (IPCC 2007), are already projected to lead to large amounts of coral loss for this area. We are not suggesting that coral communities with less than $10 \%$ coral cover should be "abandoned" or excluded from coral reef conservation and management plans. Indeed, these areas could contain important refugia for resilient corals that could be used in coral restoration efforts. We point out this potential threshold because of its implications for community structure and the provision of ecosystem services (discussed further below).

A further point worth noting is that as the reefs are further stressed, community composition and structure will continue to change, often dramatically. All of the reports of the 2005 events noted that mortality was high (sometimes nearly total) for certain taxa, such as Millepora, Agaricia, Diploria, P. porites, and Montastrea (Wilkinson and Souter 2008) while other taxa either never bleached or recovered from bleaching. Given the value of coral reefs as ecosystems with high biodiversity (Knowlton 2001b), the loss of this diversity is itself an important consequence of bleaching. It is certainly possible that a few percent of corals will show successful adaptation or survive in particularly favorable microhabitats. Thus, we are not predicting the complete loss of corals when considered at the organism or taxon level, but highly diverse, viable reef communities in the Eastern Caribbean seem likely to disappear within the lifetime of a single human generation.

The conversion of coral reefs to fundamentally different systems will have large implications for the provision of ecosystem services (Moberg and Folke 1999; Burke and Maidens 2004). These changes could result in significant economic losses, particularly for island and coastal populations whose livelihoods are closely dependent upon coral reefs and the ecosystem services they provide. For example, a study prior to the 2005 bleaching event suggested that continued coral reef degradation in the Caribbean could reduce the benefits derived from these ecosystems by $\$ 350-850$ million per year (Burke and Maidens 2004). A recent study by the World Bank used Сомво runs and economic analysis to suggest that a $90 \%$ loss of coral in the Caribbean would lead to direct economic losses of \$8.7-12 billion dollars in 2008 dollars (Vergara et al. 2009).

Given the likely future impacts of climate change on Caribbean coral reefs, it is clear that urgent action is needed to mitigate these impacts as much as possible. Recognizing this need worldwide, the International Union for Conservation of Nature (IUCN) established a Marine Working Group on Climate Change and Coral Reefs (CCCR), with the specific purpose of addressing the issue of resilience, coral reefs, and climate change. The idea of the working group is to provide the conservation and management community with tools to help identify and measure resilience for coral reefs and to promote the development of conservation and management plans that enhance resilience to climate change (IUCN 2009). For example, sites could be prioritized for conservation if they exhibit the physical features that increase resistance to bleaching (such as exposed ocean locations instead of enclosed reefs; Buddemeier et al. 2008), and if they have good local environmental conditions, such as a lack of pollution or disease. A recent report has looked extensively at resiliency for Indian Ocean coral reefs (Obura et al. 2008). Given the modeling results presented here, urgent efforts are needed to identify and protect what appear to be the most resilient coral reefs in the Caribbean. Although the extent to which these efforts could reduce wide-spread bleaching impacts is unknown, any actions that could increase the cover or extent of remnant populations will benefit science and posterity. 
Acknowledgements We gratefully acknowledge the financial support of the U.S. Environmental Protection Agency's Office of Atmospheric Programs (Contract \# GS10F0299K) and Office of Research and Development (STAR Grant \#R832224 to P.L. Jokiel). Technical contributions and/or project support were provided by Shawn Saving and Carolyn Wagner; Mark Schoneweis prepared the illustrations. We thank Caroline Rogers for helpful comments on an earlier version of the manuscript.

Open Access This article is distributed under the terms of the Creative Commons Attribution Noncommercial License which permits any noncommercial use, distribution, and reproduction in any medium, provided the original author(s) and source are credited.

\section{References}

Baker AC, Glynn PW, Riegl B (2008) Climate change and coral reef bleaching: an ecological assessment of long-term impacts, recovery trends, and future outlook. Estuar Coast Shelf Sci 80:435-471

Bouchon C, Portillo P, Bouchon-Navaro Y, Max L, Hoetjes P, Brathwaite A, Roach R, Oxenford H, O'Farrell S, Day O (2008) Status of coral reefs of the Lesser Antilles after the 2005 coral beaching event. In: Wilkinson C, Souter D (eds) Status of Caribbean coral reefs after bleaching and hurricanes in 2005. Global Coral Reef Monitoring Network, and Reef and Rainforest Research Centre, Townsville, pp 85-103

Buddemeier RW, Smith SV (1988) Coral reef growth in an era of rapidly rising sea level: predictions and suggestions for long-term research. Coral Reefs 7:51-56

Buddemeier RW, Jokiel PL, Zimmerman KM, Lane DR, Carey JM, Bohling GC, Martinich JA (2008) A modeling tool to evaluate regional coral reef responses to changes in climate and ocean chemistry. Limnol Oceanogr Methods 6:395-411

Burke L, Maidens J (2004) Reefs at risk in the Caribbean. World Resources Institute, Washington, DC

Casey KS, Cornillon P (1999) A comparison of satellite and in situ based sea surface temperature climatologies. J Climate 12:1848-1863

Causey B (2008) Coral reefs of the U.S. Caribbean-the history of massive coral bleaching and other perturbations. In: Wilkinson C, Souter D (eds) Status of Caribbean coral reefs after bleaching and hurricanes in 2005. Global Coral Reef Monitoring Network, and Reef and Rainforest Research Centre, Townsville, pp 61-67

CoastWatch (2009) Pathfinder version 5.0 sea surface temperature: dataset summary. Available http://coastwatch.pfeg.noaa.gov/infog/PH_ssta_las.html. Accessed 5 Jan 2009

Costanza R, d'Arge R, de Groot R, Farber S, Grasso M, Hannon B, Limburg K, Naeem S, O'Neill RV, Paruelo J, Raskin RG, Sutton P, van den Belt M (1997) The value of the world's ecosystem services and natural capital. Nature 387:253-260

Donner SD, Skirving WJ, Little CM, Oppenheimer M, Hoegh-Guldberg O (2005) Global assessment of coral bleaching and required rates of adaptation under climate change. Glob Chang Biol 11:2251-2265

Donner SD, Knutson TR, Oppenheimer M (2007) Model-based assessment of the role of humaninduced climate change in the 2005 Caribbean coral bleaching event. Proc Nat Acad Sci 104:5483-5488

Harriott VJ, Banks SA (2002) Latitudinal variation in coral communities in eastern Australia: a qualitative biophysical model of factors regulating coral reefs. Coral Reefs 21:83-94

Hoegh-Guldberg O (1999) Climate change, coral bleaching and the future of the world's coral reefs. Mar Freshw Res 50:839-866

IPCC (2001) Climate change 2001: the scientific basis. In: Houghton JT, Ding Y, Griggs DJ, Noguer M, van der Linden PJ, Dai X, Maskell K, Johnson CA (eds) Contribution of working group I to the third assessment report of the intergovernmental panel on climate change. Cambridge University Press, Cambridge, UK and New York, NY, USA, 881 pp

IPCC (2007) Climate change 2007: the physical science basis. In: Solomon S, Qin D, Manning M, Chen Z, Marquis M, Averyt KB, Tignor M, Miller HL (eds) Contribution of working group I to the fourth assessment report of the intergovernmental panel on climate change. Cambridge University Press, Cambridge and New York, 996 pp 
IUCN (2009) Climate change and coral reefs marine working group (CCCR). Available http://www. iucn.org/cccr/. Accessed 17 Mar 2009

Jeffrey C, Clark R, Woody K, Menza C, Caldow C, Kendall M, Monaco M (2006) Coral bleaching and recovery observed at Buck Island, St. Croix, US Virgin Islands, October and December, 2005. Center for Coastal Monitoring and Assessment, NOAA. Available http://ccma.nos.noaa. gov/products/biogeography/coral_bleaching/welcome.html. Accessed 15 Feb 2009

Jones AM, Berkelmans R, van Oppen MJH, Mieog JC, Sinclair W (2008) A community change in the algal endosymbionts of a scleractinian coral following a natural bleaching event: field evidence of acclimatization. Proc R Soc B-Biol Sci 275:1359-165

Kilpatrick KA, Podesta GP, Evans R (2001) Overview of the NOAA/NASA advanced very high resolution radiometer pathfinder algorithm for sea surface temperature and associated matchup database. J Geophys Res Oceans 106:9179-9197

Kinsey DW (1985) Metabolism, calcification, and carbon production: I. Systems level studies. In: Proceedings, fifth international coral reef congress (Tahiti), vol 4, pp 505-526

Kleypas JA, Buddemeier RW, Archer D, Gattuso JP, Langdon C, Opdyke BN (1999) Geochemical consequences of increased atmospheric carbon dioxide on coral reefs. Science 284:118-120

Kleypas JA, Buddemeier RW, Gattuso JP (2001) The future of coral reefs in an age of global change. Int J Earth Sci (Geol Rundsch) 90:426-437

Knowlton N (2001a) The future of coral reefs. Proc Nat Acad Sci 98:5419-5425

Knowlton N (2001b) Coral reef biodiversity: habitat size matters. Science 292:1493-1495

Langdon C, Takahashi T, Sweeney C, Chipman D, Goddard J, Marubini F, Aceves H, Barnett H, Atkinson MJ (2000) Effect of calcium carbonate saturation state on the calcification rate of an experimental coral reef. Glob Biogeochem Cycles 14:639-654

Liu G, Strong AE, Skirving W (2003) Remote sensing of sea surface temperatures during 2002 Barrier Reef coral bleaching. Eos Trans AGU 84:137-144

Llewellyn G (1998) Why preserve biodiversity? Building an economic case for preserving coral reefs. J Coast Dev 2:319-328

Millennium Ecosystem Assessment (2005) Ecosystems and human well-being: synthesis. Island Press, Washington, DC

Moberg F, Folke C (1999) Ecological goods and services of coral reef ecosystems. Ecol Econ 29:215233

NOAA (2008) Satellite coral bleaching monitoring datasets. Coral Reef Watch - NOAA Satellite and Information Service, National Environmental Satellite, Data, and Information Service. Available http://coralreefwatch.noaa.gov/satellite/hdf/index.html. Accessed 1 Nov 2008

NOAA (2009) Extended reconstructed sea surface temperature (ERSSTV2). NOAA Satellite and Information Service, National Environmental Satellite, Data, and Information Service. Available http://www.ncdc.noaa.gov/oa/climate/research/sst/ersstv2.php. Accessed 5 Jan 2009

NOAA-IRI (2009) NOAA NCEP EMC CMB GLOBAL Reyn_SmithOIv2 monthly (dataset access page). NOAA - International Research Institute. Available http://iridl.ldeo.columbia.edu/ SOURCES/.NOAA/.NCEP/.EMC/.CMB/.GLOBAL/.Reyn_SmithOIv2/.monthly/. Accessed 5 Jan 2009

Obura DO, Tamelander J, Linden O (eds) (2008) Ten years after bleaching - facing the consequences of climate change in the Indian Ocean. CORDIO Status Report 2008. CORDIO (Coastal Oceans Research and Development in the Indian Ocean)/Sida-SAREC. Mombasa. 489 pp. Available http://www.cordioea.org. Accessed 15 Feb 2009

Oxenford HA, Roach R, Brathwaite A, Nurse L, Goodridge R, Hinds F, Baldwin K, Finney C (2008) Quantitative observations of a major coral bleaching event in Barbados, Southeastern Caribbean. Clim Change 87:435-449

Rayner NA, Parker DE, Horton EB, Folland CK, Alexander LV, Rowell DP, Kent EC, Kaplan A (2003) Global analyses of sea surface temperature, sea ice and night marine air temperature since the late nineteenth century. J Geophys Res 108:4407. doi:10.1029/2002JD002670

Reynolds RW, Rayner NA, Smith TM, Stokes DC, Wang W (2002) An improved in situ and satellite SST analysis for climate. J Clim 15:1609-1625

Riegl BM, Purkis SJ (2009) Model of coral population response to accelerated bleaching and mass mortality in a changing climate. Ecol Model 220:192-2008

Rogers CS (2008) Coral diseases following massive bleaching in 2005 cause 60 percent decline in coral cover and mortality of the threatened species, Acropora Palmata, on reefs in the U.S. Virgin Islands. US Geological Survey Fact sheet 2008-3058 (2). Available http://pubs.usgs.gov/fs/ 2008/3058/. Accessed 15 Feb 2009 
Rogers CS, Miller J, Muller EM, Edmunds P, Nemeth RS, Beets JP, Friedlander AM, Smith TB, Boulon R, Jeffrey CFG, Menza C, Caldow C, Idrisi N, Kojis B, Monaco ME, Sptizack A, Gladfelter EH, Ogden JC, Hillis-Starr Z, Lundgren I, Schill WB, Kuffner IB, Richardson LL, Devine BE, Voss JD (2008) Ecology of coral reefs in the US Virgin Islands. In: Riegl BM, Dodge RE (eds) Coral reefs of the USA. Springer Science+Business Media B.V., pp 303-373

Sheppard CRC (2003) Predicted recurrences of mass coral mortality in the Indian Ocean. Nature 425:294-297

Smith SV, Buddemeier RW (1992) Global change and coral reef ecosystems. Ann Rev Ecol Sys 23:89-118

Smith TM, Reynolds RW (2004) Improved extended reconstruction of SST (1854-1997). J Clim $17: 2466-2477$

Spalding MD, Grenfell AM (1997) New estimates of global and regional coral reef areas. Coral Reefs 16:225-230

Strong AE, Barrientos CS, Duda C, Sapper J (1997) Improved satellite techniques for monitoring coral reef bleaching. In: Proc 8th Int'l Coral Reef Sym, vol 2, pp 1495-1498

Thornhill D, LaJeunesse T, Kemp D, Fitt W, Schmidt G (2006) Multi-year, seasonal genotypic surveys of coral-algal symbioses reveal prevalent stability or post-bleaching reversion. Mar Biol 148:711-722. doi:10.1007/s00227-005-0114-2

UK Meteorological Office - Hadley Centre (2006) HadISST 1.1 - Global sea-ice coverage and SST (1870-present). British Atmospheric Data Centre. Available http://badc.nerc.ac.uk/data/hadisst/. Accessed 30 Nov 2008

UNFCCC (2009) The United Nations Framework Convention on Climate Change. Available: http://unfccc.int/essential_background/convention/background/items/1349.php. Accessed 1 Apr 2009

Vergara W, Toba N, Mira-Salama D, Deeb A (2009) The potential consequences of climate-induced coral loss in the Caribbean by 2050-2080. In: Vergara W (ed) Assessing the potential consequences of climate destabilization in Latin America, vol 32. World Bank, Washington, DC

Vezina A, Hoegh-Guldberg O (2008) Theme section: effects of ocean acidification on marine ecosystems. Mar Ecol Prog Ser 373:199-309

Walton CC, Pichel WG, Sapper JF, May DC (1998) The development and operational application of nonlinear algorithms for the measurement of sea surface temperatures with the NOAA polarorbiting environmental satellites. J Geophys Res C12(103):27999-28012

Wigley TM (2004) MAGICC/SCENGEN 4.1: technical manual. Available http://www.cgd.ucar.edu/ cas/wigley/magicc/installation.html. Accessed 30 Nov 2008

Wilkinson C, Souter D (eds) (2008) Status of Caribbean coral reefs after bleaching and hurricanes in 2005. Global Coral Reef Monitoring Network, and Reef and Rainforest Research Centre, Townsville, $152 \mathrm{pp}$

Woody K, Atkinson A, Clark R, Jeffrey C, Lundgren I, Miller I, Monaco M, Muller E, Patterson M, Rogers C, Smith T, Spitzak T, Waara R, Whelan K, Witcher B, Wright A (2008) Coral reefs of the U.S. Caribbean - coral bleaching in the U.S. Virgin Islands in 2005 and 2006. In: Wilkinson C, Souter D (eds) Status of Caribbean coral reefs after bleaching and hurricanes in 2005. Global Coral Reef Monitoring Network, and Reef and Rainforest Research Centre, Townsville, pp 68-84

Wooldridge SA, Done T (2004) Learning to predict large-scale coral bleaching from past events: a Bayesian approach using remotely sensed data, in-situ data, and environmental proxies. Coral Reefs 23:96-108 